Research Article

\title{
Who Is the Keyman? Integrating Two-Stage DEA and Social Network Analysis to Evaluate Operational and Environmental Efficiency in the Semiconductor Industry
}

\author{
Tzu-Yi Fang (id \\ Department of Political Science, Fu Hsing Kang College, National Defense University, Taoyuan, Taiwan \\ Correspondence should be addressed to Tzu-Yi Fang; brianfang0427@gmail.com
}

Received 14 August 2020; Revised 30 October 2020; Accepted 24 November 2020; Published 9 December 2020

Academic Editor: Kuei-Hu Chang

Copyright ( 2020 Tzu-Yi Fang. This is an open access article distributed under the Creative Commons Attribution License, which permits unrestricted use, distribution, and reproduction in any medium, provided the original work is properly cited.

\begin{abstract}
The study considers the semiconductor industry's business process to be made up of two stages. In the business development process, a company generates profit and consumes energy while polluting the environment. After the two-stage data envelopment analysis approach was employed for calculating the operational efficiency and environmental efficiency, social network analysis was used to compare the manner in which the internal advantages or individual process factors of 28 semiconductor companies contribute to efficiency. A network graph was plotted to visualize relationships, with each node in the network graph representing a company. This graph was plotted to help decision-makers and manufacturers understand information communication among companies and the importance of the company in the network and help companies develop a mutual understanding to improve operational efficiency. The results of the study indicated that having an efficient company does not necessarily mean that the company plays a key role in the entire industry. The results provide decision-makers with references for improvements and information for learning from these references.
\end{abstract}

\section{Introduction}

A report by Semiconductor Equipment and Materials International (SEMI) noted that Taiwan's semiconductor industry chain is playing an increasingly important role globally. The annual total output of the global semiconductor industry is expected to increase by $3.3 \%$ in 2020 . The growth rate of Taiwan's semiconductor industry is expected to be even higher, reaching 16.7\%; its total output value is estimated to be over 3 trillion TWD. The current total output of Taiwan is more than that of South Korea, and its total output is behind only that of the United States. The development of emerging technologies is mostly because of the semiconductor industry [1]. Terminal devices to cloud architecture all rely on semiconductor technology as the foundation [2]. Taiwan has the most advanced semiconductor industry cluster in the world, and therefore, it continues to play a key role in the global industry.
High operational efficiency leads to growth in operating income and improvement in profitability, which is key to the sustainable operation of enterprises [3]. However, owing to the increasingly strict environmental regulations and the advanced production processes adopted by semiconductor companies, the demand for raw materials has increased significantly, and there has been considerable capacity expansion. As a result, the total amount spent on waste treatment per year continues to increase [4].

Performance evaluation is used to measure the performance of an organization and its employees, and the results are used to modify the organizational strategy and direction to improve the overall goals of the enterprise [5]. Performance usually involves efficiency and effectiveness. Efficiency refers to the measurement of the ratio of output to input. That is, the number of people, expenses, and costs required to achieve a goal are quantified [6]. Effectiveness refers to the extent to which a goal is achieved. That is, the actual results are compared with the target results. To 
increase their own market competitiveness and reduce the risk of mismanagement, companies rank themselves after calculating their own efficiency and the efficiencies of their competitors every year to improve internal deficiencies [7].

However, traditional ranking approaches fail to accurately capture the corporate relationship of the companies competing and cooperating with one another [8]. Performance evaluation visualization is considered a suitable alternative for enabling decision-makers to understand the business status of an enterprise in a more simple and clear manner [9]. Freeman [10] proposed the use of visual images to present corporate relationships to decision-makers or investors. They proposed the use of visual images to point out that operating efficiency is no longer a packed data resource, but a more simple and understandable resource, which allows decision-makers to observe it and apply it to business planning. In social network analysis (SNA), the concept of interconnected relationships is employed [8]. As long as they are relevant, relationships can be visualized [11]. Shape and centrality indices are used to indicate the status of a specific node in a network to allow researchers to easily understand the relationship [12]. Therefore, in this study, we used SNA to present the relationship benchmarking of companies to help decision-makers and manufacturers understand information communication. A company and its importance in the network are graphically presented to investigate the effectiveness and relationship of each company to enable decision-makers to make effective decisions.

SNA is usually used to evaluate project performance in complex cooperation systems $[13,14]$. It helps determine the performance of a project by establishing the social structure of the connections and roles involved and helps evaluate the importance of project performance and personal performance [11]. This is achieved through measures such as centrality analysis, community detection, and information diffusion analysis. In SNA, a social network is formed among social nodes through various relationships [12]. Social nodes may be individuals, countries, or even economies. These social nodes form social networks via various relationships [15]. Therefore, the object of a social network discussion is the relationships formed among individuals and not the individuals themselves.

The network view reshapes traditional theoretical understanding by shifting the research focus from being enterprise-centric to a more relational, contextual, and systematic level [16]. However, although the network view has been applied more and more theoretically, very few systematic and empirical analyses of a network in the industrial environment have been performed [17].

Although there is an increasing awareness of the opportunities and importance of network relationships for enterprises in the management field [18], the impact of the structure of network relationships on the operations of enterprises has not been fully determined. This is mainly because, in previous performance evaluation processes, enterprises were considered as homogeneous, and the focus was mainly on the performance of the enterprises themselves rather than on the interactions and interdependence among enterprises. Therefore, if the basic structural patterns of a social situation are not understood, the efforts in the management field to understand the situation may be ineffective and flawed [19]. Therefore, analytical tools are required to analyze network regularity within a social structure to develop enterprise network relations. This would reveal the interdependence among enterprise activities and thus allow us to have a more detailed understanding of the network. Past studies have neglected the characteristics of the relationship structure of these individuals. SNA is different from traditional data collection forms and emphasizes that other individuals are defined by relationships rather than by their own attributes $[11,13]$. The focus of observation is the structure of the connection. The relationships themselves are as important as individuals.

Data envelopment analysis (DEA) is a nonparametric method for measuring production efficiency. DEA is used when there are multiple inputs and multiple outputs. Charnes et al. [20] first described the method in its current form. First, an efficient frontier consisting of decisionmaking units (DMUs) demonstrating best practices is established, after which the efficiency level is assigned to other nonboundary units based on the relative distance between the DMUs and the efficient frontier. DEA has many advantages in efficiency measurement. First, unlike in a parametric method, in DEA, the functional form of the efficient frontier need not be assumed. Second, in DEA, multiple inputs and multiple outputs can be handled, and multiple inputs and multiple outputs are quite common in most applications. Third, in DEA, any real-world problem can be solved with clearly defined inputs and outputs. Fourth, DEA can be applied to various levels of aggregation. A DMU may be a company, organization, system, or country $[21,22]$.

The contributions of the study are as follows. On a theoretical level, the study expands the research perspective of the semiconductor industry and analyzes the operating performance of the semiconductor industry by integrating economic and environmental perspectives. The relationship pattern of a group of people, departments, or organizations is investigated using the quantitative analysis method of SNA. The aim is to understand the relationship status of these companies and determine the relationship from the latent structure of the social network. SNA is also used for studying the impact of these relationships on the semiconductor industry, analyzing the dynamic relationships between industries, transforming intercompany interactions into graphical presentations, and calculating relevant indicators to explore the degree to which intercompany relationships develop. The performance of the semiconductor industry's economic and environmental factors can be reviewed through social networks. For the industry as a whole, understanding the core performance will help forecast trends and help plan for the future. Therefore, the study contributes to the theoretical innovation and interpretation of the semiconductor industry structure.

From a practical point of view, past studies have focused on the internal development of enterprises and methods to improve the enterprise's performance. However, these studies have ignored the interactions among enterprises in 
the industry $[1,23,24]$. Using DEA, we explored the network relationship of the efficiency of the semiconductor industry from different stages and aspects. A discussion of the network relationships helps understand not only the overall efficiency but also the operating efficiency and environmental efficiency through network efficiency analysis methods. This is essential for understanding the main axis of industrial development, the actors playing supporting roles, and the actors playing the key roles. An individual company is aware of its strengths and shortcomings in the industry; therefore, it can develop different operating strategies, such as strengthening and consolidating existing positions or improving efficiency.

\section{Literature Review}

2.1. Performance Evaluation through DEA. DEA involves the use of multiple inputs and multiple outputs. Through DEA, relative efficiency indicators can be obtained, resource usage can be understood, and goals can be improved $[25,26]$. Ray and Das [27] used DEA to measure the efficiency changes in Indian banks after the financial reforms; they found that the profitability of banks varied considerably. State-owned banks were found to be more efficient than private banks. They also found that the smaller the size of the bank was, the lower the efficiency was. Hu et al. [28] used three input items (deposits, employees, and fixed assets) and two output items (investment and loans) to calculate the efficiency of 11 national banks in China. The impact of environmental factors was excluded, and the results showed that stateowned banks had more room for improving efficiency, which means that joint-stock banks are at an advantage in China. Therefore, state-owned banks can reform the equity ownership system to improve their efficiency. From the literature, we learn that DEA has been widely used in organizational performance measurement [29]. In addition, DEA provides a common point of view for measuring performance goals, allowing for a more complete measurement model for performance [30-32].

Marques et al. [33] employed the DEA model to study the impact of industrial and environmental factors on the operating efficiency of Japanese water companies. Li and Lin [34] used DEA to study the impact of energy-saving policies on the green productivity of Chinese manufacturing companies. Stewart et al. [35] used DEA to study the operating efficiency of the Vietnamese banking and financial system. Geng et al. [33] used a three-stage DEA model to study the investment efficiency of China's tourism industry in 2011.

Past studies have confirmed that DEA is effective in the evaluation of environmental efficiency [36]. Hatami-Marbini et al. [37] presented a case study of the semiconductor industry to prove the applicability of their proposed model and the effectiveness of the algorithm. Li et al. [38] measured the technical efficiency, scale efficiency, and innovation technology efficiency of China's semiconductor industry from 2009 to 2014. Tajbakhsh and Hassini [39] proposed a two-stage DEA model to evaluate the efficiency of power generation facilities. Sueyoshi and Yuan [40] proposed a new DEA intermediate approach to measure the sustainability of
Asian countries from 2008 to 2014. Therefore, in this study, we used the performance evaluation model to conduct an empirical analysis of the semiconductor industry.

2.2. SNA. SNA is commonly used in network theory, which is mainly used for studying network structure problems $[8,11]$. In SNA, dots represent actors, lines represent the relationship between points and points, and the graphics formed by dots and lines represent the collection and style of social networks [41]. SNA is mainly used to investigate social phenomena and structures through the relationship between actors; therefore, SNA is widely used in sociology to study social structure, political structure, organizational structure, and economic structure $[15,42]$. When researchers conduct SNA, they often use analysis software such as NetMiner, Pajek, and UCINET $[8,11,19]$. The process involved in SNA is divided broadly into three steps. In the first step, the research subjects and the network boundary are determined. In the second step, data are collected. In the third step, the network relationship attributes are analyzed. Before performing a network analysis, we must determine whether the actor unit to be studied is an individual, an organization, or a country [43]. To make the research topics clearer and the analysis results meaningful, we must define the network boundary. The boundaries of the network can be defined from a realist perspective, in which the boundary is constructed through the subjective perceptions of the network system by actors in the network, or from a nominalist perspective, in which the boundary range is defined based on the researcher's research concept or analysis purpose [44].

The social network structure is used for explaining the social behaviors of organizations [42]. In business activities, if each enterprise is taken as the central point, then that enterprise and other enterprises in the market will form connections through direct or indirect business activities, forming specific business relationships [1]. These relationships are interpreted as the enterprise's social behaviors, and these relationships are interconnected because of the needs of enterprises and the formation of networks because of these needs [8]. Sinnema et al. [15] found that SNA is a unique analysis method for visualizing the relationship structure among organizations. The visualization of the relationship structure enhances organizational development. Li et al. [45] used SNA network diagrams to represent efficiency in decision-making. Liu and Lu [46] first analyzed the efficiency of the assessed unit through DEA. Then, to examine the relationship within the assessed unit and provide references for the future development of each organization, they employed SNA. Through the indicators of SNA, the relationship among departments was found, and the relationship among departments was presented to managers through SNA and unique relationship diagrams. SNA has been combined with other analysis methods. For example, Liu et al. [47] conducted a two-stage evaluation of 40 Internet companies. First, 21 different input and output combinations were sorted using the variable returns to scale model of DEA, after which the benchmark learning subjects of each company were identified, weighed, and used as the 
basis for SNA connection. In the second stage, an efficiency network was built, and the eigenvector centrality indicator was used to calculate the proximity to important nodes. When a node had an extremely high eigenvector value, it affected other adjacent nodes. The eigenvector centrality index was used to rank the most powerful companies in the network. The results of the research provided an alternative ranking of companies, and a good model for companies that need improvement was developed. Lee et al. [48] studied the R\&D performance impact of the Korean science and engineering cooperation model and analyzed the structural position of the social network and the relationship characteristics of single nodes (characteristic orientation and closeness). The results showed that excessive cohesion might hinder development. In summary, SNA has been widely used in many different domains, and as long as it is relevant, a relationship can be visualized. Shape and centrality indicators (process, intermediary, tightness, etc.) are used to indicate the status of a specific node in a network; in this manner, researchers can easily understand the relationship. Therefore, we present an enterprise relationship benchmarking through SNA to provide enterprise decisionmakers with an alternative perspective.

\section{Methodology}

3.1. Data Collection. Previous studies have shown that the performance of enterprises in terms of environmental protection has an impact on the competitiveness of the semiconductor industry [37]. Halkos and Petrou [49] studied EU waste emissions from the perspective of regional development. They found that energy use, $\mathrm{CO}_{2}$ emissions, solid waste generation, wastewater discharge, and exhaust gas emissions were common sources of environmental pollution [50]. Therefore, we considered undesirable outputs such as greenhouse gas emissions to completely understand the development of efficiency. As seen in Figure 1, according to modern economics, the operation development process is the first stage, of which operating expenses, employees, and fixed assets are all important production factors. The output of financial and labor resources in the first stage determines a company's operational development results. The second stage, which is environmental efficiency, focuses on reducing environmental pollution, including undesirable industrial emissions (effluent drainage, waste, and greenhouse gases), and managing resources. This research referred to existing literature $[1,40,51,52]$ and followed industrial production practices to select input and output variables.

We used data from 28 companies in the semiconductor industry from 2014 to 2017 to measure efficiency. The semiconductor industry chain is usually divided into three major sectors: upstream (e.g., design of integrated circuits (ICs)), midstream (e.g., wafer fabrication), and downstream (e.g., IC packaging and testing). Because wafer fabrication is the main cause of environmental pollution in the semiconductor industry, we focused on companies in the midstream sector of the industry and discussed their operational and environmental efficiencies. The factors considered are described as follows. The Corporate Social Responsibility
Report released by various companies, including continuous improvement projects in the fields of climate change, energy management, water management, waste management, and air pollution control, is part of the company's voluntary information disclosure. The data of the 28 companies in the semiconductor industry were obtained from their CSR reports published in the Market Observation Post System of the Taiwan Stock Exchange. Table 1 presents the descriptive statistical analysis of the variables considered in the study.

3.2. Network DEA. The two-stage DEA model is a simple network DEA model [53]. A network is a system with multiple interconnected processes. The output of the first stage serves as the input to the second stage, known as intermediate data. The network system has two basic structures - series and parallel-and both the efficiency and deficiency of the system can be divided into the efficiency and deficiency of internal processes [53-55].

Cook et al. [53] reviewed these models and established relationships among various approaches. Their study indicated that all existing approaches could be classified as applications of the leader-follower or cooperative game theory. Chen et al. [54] developed an additive efficiency decomposition approach, which is different from the nonlinear model developed by Liang, Cook [56]. Therefore, the additive form of efficiency decomposition appears to be a more reasonable and easier-to-perform method for measuring the performance of a two-stage process under the variable returns to scale model [57].

The fundamental methods of the two-stage network DEA are the multiplicative and additive efficiency decomposition approaches. Both of them assume a series relationship between the two stages; however, they differ in terms of the definition of overall system efficiency and in terms of the conceptualization of the decomposition of the overall efficiency into each stage. Despotis et al. [55] showed that the efficiency estimates obtained using the additive decomposition method are biased, as one stage is more emphasized upon than the other. However, the estimates obtained using the multiplicative method are not unique. Therefore, Despotis et al. [55] proposed a method for estimating unique and unbiased efficiency scores for each stage, which were then composed to obtain the efficiency of the overall system by using a posteriori aggregation method.

Guo et al. [58] adopted the two-stage network structure as an example to study the additive efficiency decomposition approach. In their study, the overall efficiency was defined as the weighted average of individual stage efficiencies, and the weight indicated the relative importance of each stage. Guo et al. [58] also revealed that the weight may not affect the calculation of the efficiency scores for each stage and that the change in overall efficiency owing to the use of different weights may be related to stable stage efficiencies.

In traditional DEA, radial efficiency is measured; therefore, we assume that the input or output can be adjusted (reduced or expanded) at an equal rate, which may not be true in some cases. Therefore, Tone et al. [59] proposed the Network SBM model (slack-based measures, 


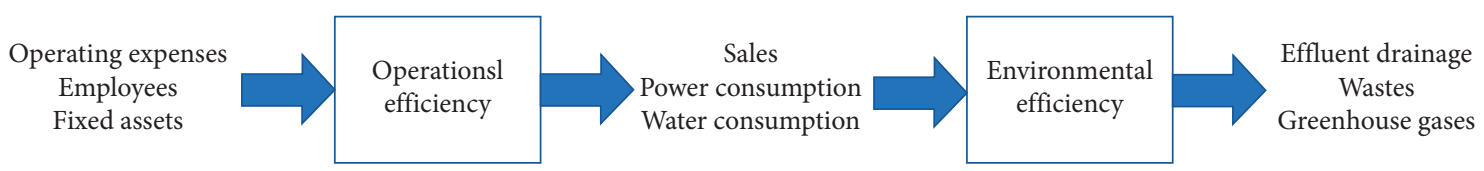

FIGURE 1: Two-stage production model of the semiconductor industry.

Table 1: Descriptive statistics.

\begin{tabular}{|c|c|c|c|c|}
\hline & Mean & Max & Min & SD \\
\hline Operating expenses (NT\$ million) & 14,276 & 87,366 & 267 & 21,446 \\
\hline Employees (persons) & 13,053 & 109,267 & 369 & 24,720 \\
\hline Fixed assets (NT\$ billion) & 74,508 & $1,062,542$ & 580 & 199,788 \\
\hline Sales (NT\$ million) & 100,434 & 977,447 & 4,078 & 193,369 \\
\hline Power consumption (terawatt hours) & 86,729 & $1,082,900$ & 7 & 205,881 \\
\hline Water consumption (tons) & $5,478,126$ & $45,200,000$ & 30,297 & $9,645,525$ \\
\hline Effluent drainage (tons) & $3,546,011$ & $29,400,000$ & 29,879 & $6,076,439$ \\
\hline Wastes (ton) & 28,352 & 361,969 & 47 & 70,786 \\
\hline Greenhouse gases (ton) & 756,329 & $6,257,020$ & 2,784 & $1,548,402$ \\
\hline
\end{tabular}

measures based on slack variables) to measure the overall efficiency and departmental efficiency of an organization. The SBM model is a nonradial efficiency measure conforming to unit invariants. This model integrates slack variables, that is, excesses in inputs and shortfalls in outputs to measure efficiency. If the input and output cannot be adjusted at an equal rate, then the SBM model is suitable for use. This model is used to calculate three types of efficiencies: input-oriented efficiency, output-oriented efficiency, and nonoriented efficiency. We employed the nonoriented efficiency to evaluate the performance of the semiconductor industry considering both input slacks and output slacks.
Assuming that $n$ is the number of DMUs evaluated, $k$ is the number of stages $(k=1, \ldots, K), t$ is the number of periods $(t=1, \ldots, T), m_{t}^{k}$ represents the number of inputs in period $t$ of stage $k, r_{t}^{k}$ represents the number of outputs in period $t$ of stage $k, x_{i o t}^{k}$ represents the input items of the oth evaluated DMU in period $t$ of stage $k, y_{\text {rot }}^{k}$ represents the output items of the oth evaluated DMU in period $t$ of stage $k,(k, h)$ represents the linkage from stage $k$ to stage $h$, and $z_{j t}^{(k, h)}$ is the intermediate input (output) linking stage $k$ and stage $h$, the relevant network DEA score planning is expressed as shown in the following equations:

$$
\begin{aligned}
& \rho_{o}^{*}= \operatorname{Min} \frac{(1 / T) \sum_{t=1}^{T} \sum_{k=1}^{\mathrm{K}} w_{t}^{k}\left[1-\left(1 / m_{t}^{k}\right)\left(\sum_{i=1}^{m_{t}^{k}} s_{i t}^{k^{-}} / s_{i t}^{k^{-}}\right)\right]}{(1 / T) \sum_{t=1}^{T} \sum_{k=1}^{K} w_{t}^{k}\left[1+1 / r_{t}^{k}\right]}, \\
& \text { s.t. } \quad x_{i o t}^{k}=\sum_{j=1}^{n} x_{i j t}^{k} \lambda_{j t}^{k}+s_{i t}^{k^{-}}, \quad i=1, \ldots, m_{t}^{k} ; t=1, \ldots, T ; k=1, \ldots, K \\
& y_{r o t}^{k}=\sum_{j=1}^{n} y_{r j t}^{k} \lambda_{j t}^{k}-s_{r t}^{k^{+}}, \quad r=1, \ldots, r_{t}^{k} ; t=1, \ldots, T ; k=1, \ldots, K \\
& \sum_{j=1}^{n} \lambda_{j t}^{k}=1, \quad t=1, \ldots, T \\
& \sum_{j=1}^{n} z_{j t}^{(k, h)} \lambda_{j t}^{h}=\sum_{j=1}^{n} z_{j t}^{(k, h)} \lambda_{j t}^{k}, \quad \forall(k, h)(t=1, \ldots, T) \\
& \lambda_{j t}^{k} \geq 0, s_{i t}^{k^{-}} \geq 0, s_{r t}^{k^{+}} \geq 0,
\end{aligned}
$$

where $\rho_{o}^{*}$ represents the overall efficiency value of DMUs in the period T. By changing the subscript $o$, the overall efficiency value of all DMUs in the period $t$ is obtained. $\sum_{j=1}^{n} x_{i j t}^{k} \lambda_{j t}^{k}$ and $\sum_{j=1}^{n} y_{r t}^{k} \lambda_{j t}^{k}$, respectively, represent the benchmark value of the efficiency boundary of the $i$ th input and $r$ th output of stage $k$ during the $t$ th period. $s_{i t}^{k^{-}}$and $s_{r t}^{k^{+}}$, respectively, represent the input slack and output slack of stage $k$ in the $t$ th period. If $\rho_{o}^{*}$ is 1 , the overall efficiency value of the $T$ th period is efficient in the balance-based 
measurement model; if $\rho_{o}^{*}$ is less than 1 , the overall efficiency value of the target DMU in the $T$ th period is nonefficient.

Furthermore, using the optimal input slack $s_{i t}^{k^{*-}}$ and the optimal output slack $s_{r t}^{k^{*+}}$ in equations (1) and (2), the nonoriented $t$-th period efficiency value is defined as follows:

$$
\rho_{t}=\frac{\sum_{k=1}^{K} w_{t}^{k}\left[1-\left(1 / m_{t}^{k}\right)\left(\sum_{i=1}^{m_{t}^{k}} s_{i t}^{k^{-}} / x_{i o t}^{k}\right)\right]}{\sum_{k=1}^{K} w_{t}^{k}\left(1+1 / r_{t}^{k}\right)} .
$$

In equation (3), $\rho_{o}=1 / T \sum_{t=1}^{T} \rho_{t}$. If the target DMU is 1 , then the target DMU is efficient in the $t$ th period. If the target DMU is less than 1 , then the target DMU is nonefficient in the period $t .0 \leq \rho_{t} \leq 1$ indicates that the SBM efficiency value is between 0 and 1 . When both $s_{i t}^{k^{-}}$and $s_{r t}^{k^{+}}$are 0 , it means that there is no slack in all input and output items of the target DMU in the period $t$ of stage $k$ :

$$
\rho_{t}^{k}=\frac{\left[1-\left(1 / m_{t}^{k}\right)\left(\sum_{i=1}^{m_{t}^{k}} s_{i t}^{k^{-}} / x_{i o t}^{k}\right)\right]}{\left(\left[1+1 / r_{t}^{k}\right]\right)} .
$$

In equation (4), $\rho_{t}=\sum_{k=1}^{K} w_{t}^{k} \rho_{t}^{k}$. If the target DMU is 1 , then the target DMU is efficient in period $t$ of stage $k$. If the target DMU is less than 1, then the target DMU is nonefficient in period $t$ of stage $k .0 \leq \rho_{t}^{k} \leq 1$ indicates that the SBM efficiency value is between 0 and 1 . When both $s_{i t}^{k^{-}}$and $s_{r t}^{k^{+}}$are 0 , it means that there is no slack in all input and output items of the target DMU in period $t$ of stage $k$.

3.3. SNA. The underlying social network structure is found by analyzing the patterns of relationships and the interactions between social actors [60]. Borgatti and Cross [61] further pointed out that SNA is formed by linking actors with each other, using lines to denote the relationships. Therefore, through the network structure diagram formed by nodes (actors) and their relationship linkages, it is possible to understand the social network characteristics of the actors and observe the impact of these characteristics on the organization. Today, SNA is employed for studying social organization, business management, and information dissemination. The indicators for measuring centrality include degree, closeness, and betweenness [62, 63]. To ensure consistency in the measurement results, we adopted Freeman's view and measurement method for defining degree, closeness, and betweenness. The network centrality indicators are described as follows:

Degree centrality: this is used to measure the degree to which a node of the network has a large band in the network. Degree can be categorized as In-Degree and Out-Degree. In-Degree represents the number of nodes connected to other nodes in the network, and OutDegree represents the number of nodes connected to a particular node. The higher the degree of a node, the greater number of nodes it can influence or be affected by in the network. The equation for calculating InDegree is as follows:

$$
C_{d}\left(n_{i}\right)=\frac{d\left(n_{i}\right)}{a-1}
$$

where $n_{i}$ is a DMU, $d\left(n_{i}\right)$ is the degree of $n_{i}$, and $a$ is the number of nodes in the entire network.

Closeness centrality: To focus on the distances from each node to other nodes, it considers the indirect connection system to measure all points of the overall network, which can be used to judge the closeness of a node to other nodes. The value is between 0 and 1 . The higher the closeness value is, the more important a node is because it is close to other points, and it can affect other points or be affected by other points quickly. The equation for calculating closeness is as follows:

$$
C_{c}\left(n_{i}\right)=\frac{(a-1)}{\left[\sum_{j=1}^{g} d\left(n_{i}, n_{j}\right)\right]}
$$

where $a$ is the number of nodes and $d\left(n_{i}, n_{j}\right)$ is the shortest distance from $n_{i}$ to $n_{j}$.

Betweenness centrality: this is used to measure the number of times a node is along the shortest path between two other nodes in the network. The higher the betweenness value of a node is, the more likely it is to be an important point because it acts as a bridge/ broker between two nodes. The equation for calculating betweenness is as follows:

$$
C_{b}\left(n_{i}\right)=\frac{\sum_{j<k} a_{j k}\left(n_{i}\right) / a_{j k}}{[(a-1)(a-2) / 2]}
$$

where $a$ is the number of nodes, $a_{j k}$ is the shortest distance between node $j$ and node $k$, and $a_{j k}\left(n_{i}\right)$ is the shortest distance through node $n_{i}$. The maximum value is equal to the number of combinations of two randomly selected points under the total number of nodes $(a-1)$.

Eigenvector centrality: This centrality index was proposed in 1987 by Bonacich, and it is mainly used to calculate the importance of nodes in the network. The adjacency matrix is used to calculate the degree of proximity between important nodes. A node with a high eigenvector value in the network will affect adjacent nodes; therefore, the eigenvector value of the adjacent node will increase, with the value being between 0 and 1 . The equation for calculating the eigenvector centrality is as follows:

$$
C_{e}=\frac{1}{\eta} A X
$$


where $\eta$ is a constant, $A$ represents the adjacent matrix, and $X$ represents the sum of all connected points. This vector is called an eigenvector of matrix $A$. The elements of this vector are the eigenvector centralities of the vertices of the graph.

\section{Results}

4.1. Evaluation of Efficiency in the Semiconductor Industry. The average scores of efficiency values over a 4-year period are listed in Table 2, where the results of overall efficiency, operational efficiency (TE1), and environmental efficiency (TE2) are listed. The scores of relative efficiencies lie between 0 and 1. A score of 1 for the DMUs indicates that the company has been relatively efficient during each of the 4 years, whereas a score of less than 1 indicates DMUs that have been relatively inefficient. The relative efficiency of each DMU is obtained using the DEA model. Overall, the average of the three efficiencies for all companies is $0.803,0.866$, and 0.910, respectively. Ten of the companies-NTC, UMC, DELTA, TSMC, GET, FST, VIS, Wafer, FATC, and ASE- are efficient companies, and their efficiency values on the three benchmarks are all 1 . The three efficiency values for KYEC are $0.113,0.445$, and 0.254 , respectively, indicating that KYEC exhibited the worst performance.

The semiconductor industry has an environmental efficiency value of 0.910 , which is higher than the operating efficiency value of 0.866 . The research results are in line with the semiconductor industry's recent efforts to promote green management in corporate operations. The industry implements various continuous improvement actions related to climate change, energy management, water management, waste management, and air pollution prevention and control, with the aim of preventing business operations from harming the environment. However, the efficiency values obtained using the general DEA model only help to understand the performance of a company. The values do not indicate the role of a company in the industry and the relationship shares with other companies. To this end, we used SNA.

4.2. SNA for Firms in Taiwan's Semiconductor Industry. Benchmark refers to the best-in-class reference point among peers. Companies can learn from and follow a company that sets benchmarks. The method commonly used for company performance evaluation is the traditional DEA; however, this method provides multiple benchmarks. Combining DEA with the SNA method allows for the identification of companies that other companies can learn from. Therefore, after completing the performance evaluation through DEA, we considered each DMU as a node of the network to determine the most efficient company from the 28 evaluated units. According to the results of the DEA, if an efficient DMU is considered a reference object by an inefficient DMU, then there exists a reference relationship between the two DMUs. To determine the degree of difference in efficiency from the evaluated units, we used the network-based ranking method along with SNA to further rank the
TABle 2: Efficiency scores for firms in Taiwan's semiconductor industry.

\begin{tabular}{|c|c|c|c|}
\hline DMU & $\mathrm{OE}$ & TE1 & TE2 \\
\hline NTC & 1.000 & 1.000 & 1.000 \\
\hline UMC & 1.000 & 1.000 & 1.000 \\
\hline DELTA & 1.000 & 1.000 & 1.000 \\
\hline TSMC & 1.000 & 1.000 & 1.000 \\
\hline Macronix & 0.980 & 1.000 & 0.980 \\
\hline Winbond & 0.403 & 0.462 & 0.871 \\
\hline Tatung & 0.364 & 0.413 & 0.881 \\
\hline MTK & 0.916 & 0.916 & 1.000 \\
\hline Elan & 0.784 & 0.784 & 1.000 \\
\hline GET & 1.000 & 1.000 & 1.000 \\
\hline FST & 1.000 & 1.000 & 1.000 \\
\hline Nuvoton & 0.863 & 1.000 & 0.863 \\
\hline VIS & 1.000 & 1.000 & 1.000 \\
\hline SAS & 0.820 & 0.961 & 0.854 \\
\hline Chipbond & 0.494 & 0.638 & 0.774 \\
\hline Wafer & 1.000 & 1.000 & 1.000 \\
\hline FATC & 1.000 & 1.000 & 1.000 \\
\hline Greatek & 0.863 & 0.863 & 1.000 \\
\hline KYEC & 0.113 & 0.445 & 0.254 \\
\hline WSC & 0.416 & 0.423 & 0.984 \\
\hline Xintec & 0.948 & 1.000 & 0.948 \\
\hline Episil & 0.849 & 1.000 & 0.849 \\
\hline GBM & 0.960 & 0.960 & 1.000 \\
\hline PTI & 0.572 & 0.795 & 0.719 \\
\hline ChipMOS & 0.545 & 0.819 & 0.665 \\
\hline SPIL & 0.914 & 0.945 & 0.966 \\
\hline ASE & 1.000 & 1.000 & 1.000 \\
\hline PTC & 0.687 & 0.813 & 0.845 \\
\hline Mean & 0.803 & 0.866 & 0.910 \\
\hline
\end{tabular}

evaluated units. Table 3 lists the ranking results of the evaluated units.

To make it easier to interpret the results, we used the Pajek software to convert the results into a reference network diagram. Figures 2 and 3 show the accumulated reference networks for the operational efficiency and environmental efficiency stages, respectively. The purpose of drawing the network relationship diagram shown in Figure 2 is to determine efficient companies by using the DEA method and to obtain the company most suitable to learn from the semiconductor industry through the network relationship diagram. Table 3 lists the operational efficiency and environmental efficiency indices. The degree centrality is plotted in Figure 2. The highest In-Degree from the operational efficiency network was 27, which was obtained by Macronix. This means that Macronix was used as a benchmark by 27 other companies. Through the establishment of the network, DEA provides benchmark objects that each DMU can learn from. The social network centrality indicators were analyzed to understand the most influential DMUs in the network. For example, TSMC had the highest eigenvector centrality (0.5470) in the operational efficiency network. The higher the value, the higher the likelihood of the node affecting other neighboring nodes. However, the betweenness centrality of TSMC was only 0.0081. This indicates that the influence of TSMC on the operational efficiency of the entire semiconductor industry is restricted to enhancing the 
TABLE 3: Ranks and centralities of firms in Taiwan's semiconductor industry.

\begin{tabular}{|c|c|c|c|c|c|c|c|c|}
\hline \multirow[b]{2}{*}{ DMU } & \multicolumn{4}{|c|}{ Operational efficiency } & \multicolumn{4}{|c|}{ Environmental efficiency } \\
\hline & In-degree & $\mathrm{CC}$ & $\mathrm{BC}$ & EC & In-degree & CC & $\mathrm{BC}$ & $\mathrm{EC}$ \\
\hline NTC & 21 & 0.8438 & 0.0010 & 0.4084 & 17 & 0.7500 & 0.0043 & 0.7112 \\
\hline UMC & 8 & 0.6585 & 0.0186 & 0.0008 & 3 & 0.6136 & 0.0094 & 0.0163 \\
\hline DELTA & 9 & 0.6750 & 0.0061 & 0.0301 & 5 & 0.5870 & 0.0246 & 0.0159 \\
\hline TSMC & 21 & 0.8438 & 0.0081 & 0.5470 & 15 & 0.6923 & 0 & 0.2491 \\
\hline Macronix & 27 & 1 & 0.0934 & 0.4741 & 26 & 0.9643 & 0.1041 & 0.4003 \\
\hline Winbond & 2 & 0.6923 & 0.0005 & 0 & 0 & 0.6136 & 0 & 0 \\
\hline Tatung & 2 & 0.6000 & 0.0004 & 0 & 0 & 0.5870 & 0 & 0 \\
\hline MTK & 18 & 0.8438 & 0.1120 & 0.1053 & 13 & 0.6923 & 0.0058 & 0.1205 \\
\hline Elan & 14 & 0.8182 & 0.0719 & 0.0064 & 13 & 0.6923 & 0.0064 & 0.0250 \\
\hline GET & 13 & 0.7297 & 0.0096 & 0.0613 & 12 & 0.6923 & 0.0156 & 0.0789 \\
\hline FST & 21 & 0.8710 & 0.0175 & 0.1404 & 17 & 0.7714 & 0.0570 & 0.3150 \\
\hline Nuvoton & 19 & 0.7714 & 0.0145 & 0.1039 & 18 & 0.7714 & 0.0283 & 0.0869 \\
\hline VIS & 24 & 1 & 0.0542 & 0.4987 & 21 & 0.8710 & 0.0715 & 0.3530 \\
\hline SAS & 9 & 0.7105 & 0.0052 & 0.0017 & 4 & 0.6429 & 0.0030 & 0.0461 \\
\hline Chipbond & 0 & 0.6279 & 0 & 0 & 0 & 0.5870 & 0 & 0 \\
\hline Wafer & 4 & 0.6923 & 0.0027 & 0.0023 & 3 & 0.6585 & 0.0013 & 0.0021 \\
\hline FATC & 10 & 0.7297 & 0.0392 & 0.0464 & 9 & 0.6923 & 0.0755 & 0.0572 \\
\hline Greatek & 12 & 0.9643 & 0.1552 & 0.0349 & 8 & 0.7105 & 0.0310 & 0.0553 \\
\hline KYEC & 4 & 0.8182 & 0.0072 & 0 & 0 & 0.6585 & 0 & 0 \\
\hline WSC & 4 & 0.6750 & 0.0013 & 0 & 0 & 0.6136 & 0 & 0 \\
\hline Xintec & 8 & 0.6279 & 0.0032 & 0.0598 & 9 & 0.6429 & 0.0074 & 0.0378 \\
\hline Episil & 16 & 0.7500 & 0.0144 & 0.0853 & 16 & 0.7500 & 0.0220 & 0.0910 \\
\hline GBM & 4 & 0.7500 & 0.0074 & 0 & 1 & 0.6000 & 0 & 0.0001 \\
\hline PTI & 3 & 0.6923 & 0.0093 & 0 & 0 & 0.6429 & 0 & 0 \\
\hline ChipMOS & 13 & 0.7714 & 0.0076 & 0 & 2 & 0.6136 & 0.0016 & 0.0017 \\
\hline SPIL & 0 & 0.6585 & 0 & 0 & 0 & 0.6429 & 0 & 0 \\
\hline ASE & 9 & 0.6750 & 0.0044 & 0.0003 & 4 & 0.6136 & 0.0028 & 0.0205 \\
\hline PTC & 7 & 0.7297 & 0.0228 & 0 & 0 & 0.6585 & 0 & 0 \\
\hline
\end{tabular}

$\mathrm{CC}=$ closeness centrality; $\mathrm{BC}=$ betweenness centrality; $\mathrm{EC}=$ eigenvector centrality.

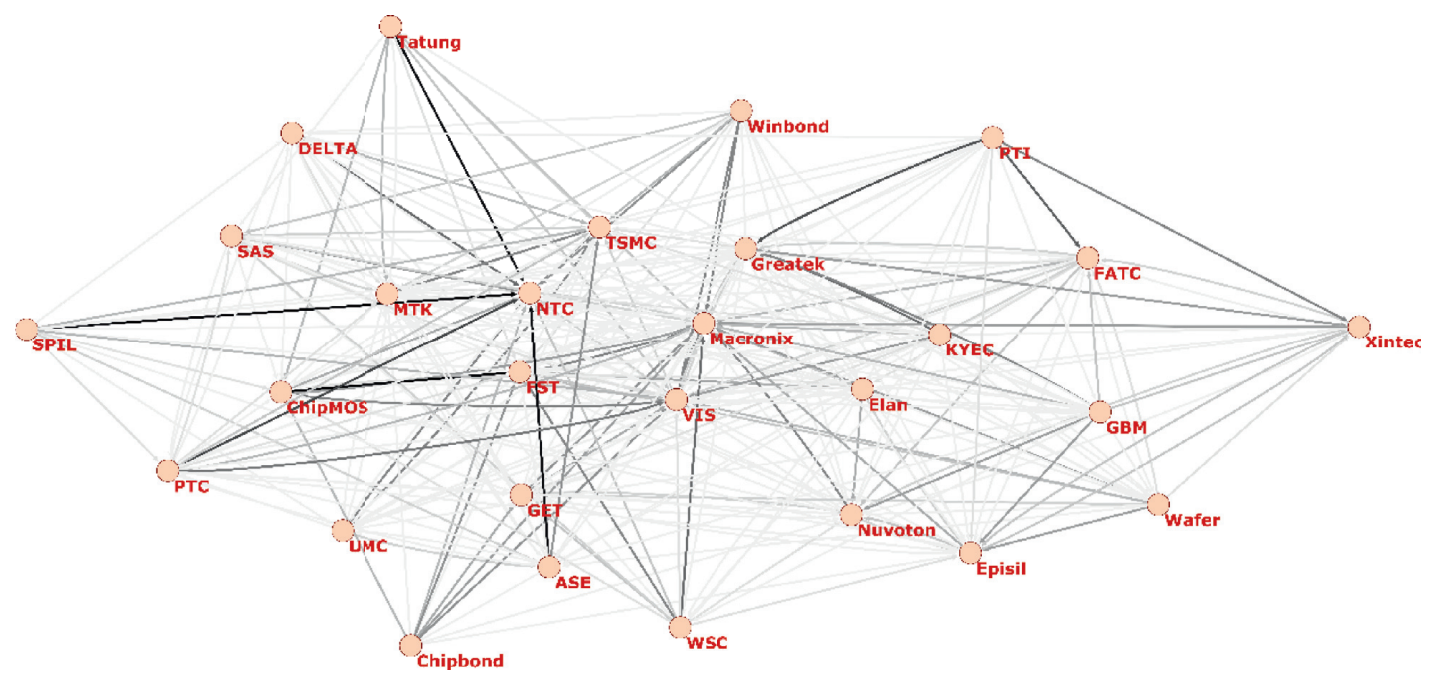

Figure 2: Reference network for the first stage. Link weights are indicated with different line thicknesses and gray levels. Darker lines indicate heavier weights. The network is drawn with Pajek software [64] using the Kamada-Kawai energy layout option.

operational performance of the other companies; TSMC does not play a role in delivering messages in the group.

In addition, Macronix was not the best performing company in terms of the efficiency values calculated using DEA. However, Macronix had the highest In-Degree value in both operational efficiency and environmental efficiency networks, indicating that it has high efficiency in corporate operations. The closeness centrality determines the closeness of a node to other nodes. The higher the closeness value of a node, the faster it can affect or be affected by other nodes.

The higher the closeness centrality value of a node in the network, the closer the distance between the node and 


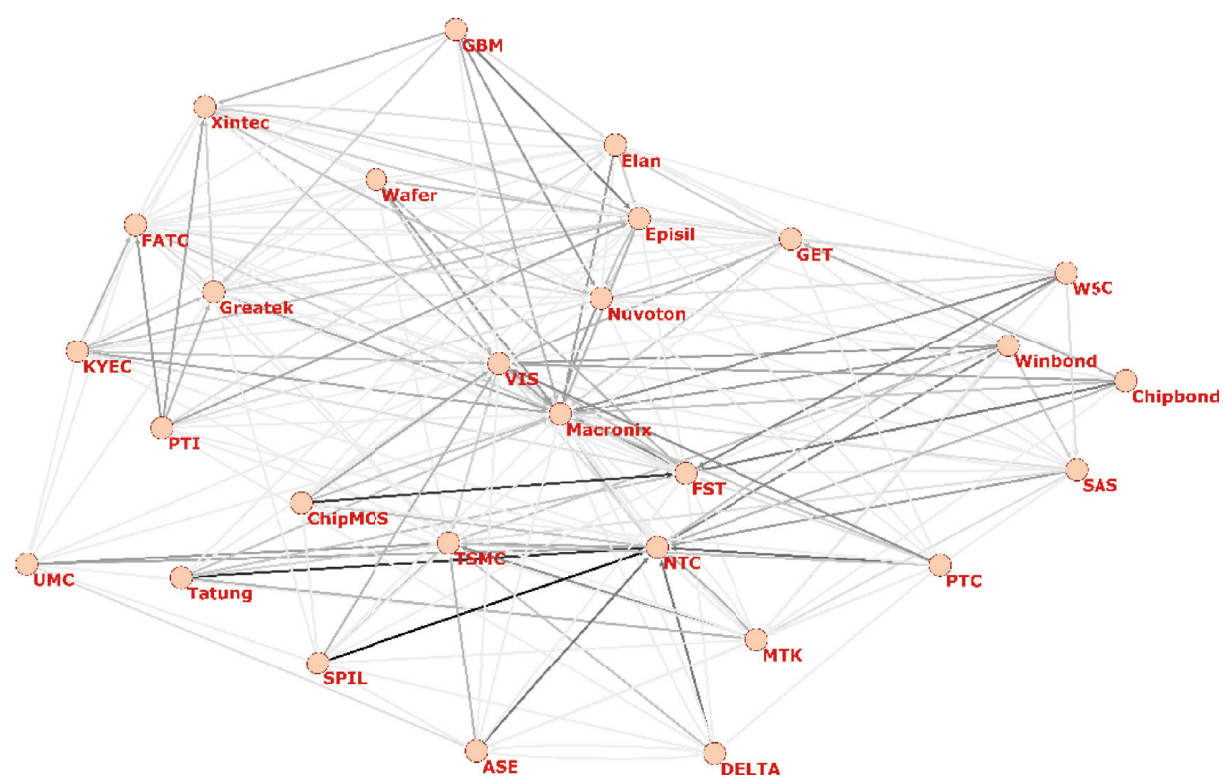

FiguRE 3: Reference network for the second stage. Link weights are indicated with different line thicknesses and gray levels. Darker lines indicate heavier weights. The network is drawn with Pajek software (Batagelj and Mrvar, 1998) using the Kamada-Kawai energy layout option.

other nodes, which means that Macronix can obtain and communicate information the fastest. Macronix had the highest closeness centrality and betweenness centrality values in the environmental efficiency network. Therefore, Macronix acts as a bridge between companies and companies in the environmental efficiency network. Moreover, it can transmit information most quickly. Therefore, Macronix is a crucial enterprise in terms of environmental efficiency.

\section{Concluding Remarks}

In past research, an enterprise was usually analyzed as an independent individual [8]. However, this analysis method ignores the relationship structure among different individuals in the semiconductor industry. In fact, these companies are not independent of one another in the industry chain. These companies not only depend on one another but also interact with one another, passing messages to one another and forming an intricate industrial network. With the advent of big data, the quality of data analysis has a major and critical impact on subsequent decision-making. Effective data integration analysis can transform data into useful information and form a decision support reference. We used SNA to evaluate whether a company has a pivotal position in operating efficiency and environmental efficiency.

\section{Data Availability}

The data of 28 companies in the semiconductor industry used to support the findings of this study have been released from their Corporate Social Responsibility reports published in the Taiwan Market Observation System. The data could be downloaded on the website of the Taiwan Stock Exchange.

\section{Conflicts of Interest}

The author declares that there are no conflicts of interest.

\section{References}

[1] C.-w. Shen, P. Tran, and P. Minh Ly, "Chemical waste management in the U.S. semiconductor industry," Sustainability, vol. 10, no. 5, p. 1545, 2018.

[2] F. Lin, S.-W. Lin, and W.-M. Lu, "Sustainability assessment of Taiwan's semiconductor industry: a new hybrid model using combined analytic hierarchy process and two-stage additive network data envelopment analysis," Sustainability, vol. 10, no. 11, p. 4070, 2018.

[3] J. A. Surroca, R. V. Aguilera, K. Desender, and J. A. Tribó, "Is managerial entrenchment always bad and corporate social responsibility always good? A cross-national examination of their combined influence on shareholder value," Strategic Management Journal, vol. 41, no. 5, pp. 891-920, 2020.

[4] F. Lin, S.-W. Lin, and W.-M. Lu, "Dynamic eco-efficiency evaluation of the semiconductor industry: a sustainable development perspective," Environmental Monitoringassessment, vol. 191, no. 7, p. 435, 2019.

[5] L.-b. Li, B.-l. Liu, W.-1. Liu, and Y.-H. Chiu, "Efficiency evaluation of the regional high-tech industry in China: a new framework based on meta-frontier dynamic DEA analysis," Socio-Economic Planning Sciences, vol. 60, pp. 24-33, 2017.

[6] T. Koltai, S. Lozano, J. Uzonyi-Kecskés, and P. Moreno, "Evaluation of the results of a production simulation game using a dynamic DEA approach," Computers \& Industrial Engineering, vol. 105, pp. 1-11, 2017.

[7] W.-M. Lu, Q. L. Kweh, D.-S. He, and J.-M. Shih, "Performance analysis of the cultural and creative industry: a network-based approach," Naval Research Logistics (NRL), vol. 64, no. 8, pp. 662-676, 2017.

[8] Y. Kurt and M. Kurt, "Social network analysis in international business research: an assessment of the current state of play 
and future research directions," International Business Review, vol. 29, no. 2, 2020.

[9] C.-H. Tsai, H.-Y. Wu, I.-S. Chen, J.-K. Chen, and R.-W. Ye, "Exploring benchmark corporations in the semiconductor industry based on efficiency," The Journal of High Technology Management Research, vol. 28, no. 2, pp. 188-207, 2017.

[10] L. C. J. J. Freeman, "Visualizing social networks," Journal of Social Structure, vol. 1, no. 1, p. 4, 2000.

[11] U. Can and B. Alatas, "A new direction in social network analysis: online social network analysis problems and applications," Physica A: Statistical Mechanics and Its Applications, vol. 535, Article ID 122372, 2019.

[12] U. Aydın, M. A. Karadayi, and F. Ülengin, "How efficient airways act as role models and in what dimensions? A superefficiency DEA model enhanced by social network analysis," Journal of Air Transport Management, vol. 82, Article ID 101725, 2020.

[13] M.-F. Hsu, C.-C. Yeh, S.-J. Lin, and S. Patnaik, "Integrating dynamic malmquist DEA and social network computing for advanced management decisions," Journal of Intelligent \& Fuzzy Systems, vol. 35, no. 1, pp. 231-241, 2018.

[14] D. Camacho, Á. Panizo-LLedot, G. Bello-Orgaz, A. GonzalezPardo, and E. Cambria, "The four dimensions of social network analysis: an overview of research methods, applications, and software tools," Information Fusion, vol. 63, pp. 88-120, 2020.

[15] C. Sinnema, A. J. Daly, Y.-H. Liou, and J. Rodway, "Exploring the communities of learning policy in New Zealand using social network analysis: a case study of leadership, expertise, and networks," International Journal of Educational Research, vol. 99, Article ID 101492, 2020.

[16] M. Forsgren and J. Johanson, Managing Networks in International Business, Routledge, Abingdon, UK, 2014.

[17] M. Yamin and Y. Kurt, "Revisiting the Uppsala internationalization model," International Marketing Review, vol. 35, no. 1, pp. 2-17, 2018.

[18] S. Michailova, "Contextualizing in international business research: why do we need more of it and how can we be better at it?" Scandinavian Journal of Management, vol. 27, no. 1, pp. 129-139, 2011.

[19] S. Monaghan, J. Lavelle, and P. Gunnigle, "Mapping networks: exploring the utility of social network analysis in management research and practice," Journal of Business Research, vol. 76, pp. 136-144, 2017.

[20] A. Charnes, W. W. Cooper, and E. Rhodes, "Measuring the efficiency of decision making units," European Journal of Operational Research, vol. 2, no. 6, pp. 429-444, 1978.

[21] T. Sueyoshi and M. Goto, "DEA environmental assessment in time horizon: radial approach for Malmquist index measurement on petroleum companies," Energy Economics, vol. 51, pp. 329-345, 2015.

[22] J. Wang, S. Wang, S. Li, Q. Cai, and S. Gao, "Evaluating the energy-environment efficiency and its determinants in Guangdong using a slack-based measure with environmental undesirable outputs and panel data model," Science of the Total Environment, vol. 663, pp. 878-888, 2019.

[23] A. Hatami-Marbini, M. Tavana, K. Gholami, and Z. G. Beigi, "A bounded data envelopment analysis model in a fuzzy environment with an application to safety in the semiconductor industry," Journal of Optimization Theory and Applications, vol. 164, no. 2, pp. 679-701, 2014.

[24] M. Romauch and R. F. Hartl, "Capacity planning for cluster tools in the semiconductor industry," International Journal of Production Economics, vol. 194, pp. 167-180, 2017.
[25] X. Liu, J. Chu, P. Yin, and J. Sun, "DEA cross-efficiency evaluation considering undesirable output and ranking priority: a case study of eco-efficiency analysis of coal-fired power plants," Journal of Cleaner Production, vol. 142, pp. 877-885, 2017.

[26] D. Torregrossa, A. Marvuglia, and U. Leopold, "A novel methodology based on LCA + DEA to detect eco-efficiency shifts in wastewater treatment plants," Ecological Indicators, vol. 94, pp. 7-15, 2018.

[27] S. C. Ray and A. Das, "Distribution of cost and profit efficiency: evidence from Indian banking," European Journal of Operational Research, vol. 201, no. 1, pp. 297-307, 2010.

[28] J.-L. Hu, W.-K. Chu, X. Hu, and C.-Y. Lee, "Operational environment-adjusted nationwide bank efficiency in China," Journal of Management Research, vol. 9, no. 3, pp. 142-158, 2009.

[29] G. E. Halkos, N. G. Tzeremes, and S. A. Kourtzidis, "Measuring sustainability efficiency using a two-stage data envelopment analysis approach," Journal of Industrial Ecology, vol. 20 , no. 5, pp. 1159-1175, 2016.

[30] X. Guo, C.-C. Lu, J.-H. Lee, and Y.-H. Chiu, "Applying the dynamic DEA model to evaluate the energy efficiency of OECD countries and China," Energy, vol. 134, pp. 392-399, 2017.

[31] A. Mardani, E. K. Zavadskas, D. Streimikiene, A. Jusoh, and M. Khoshnoudi, "A comprehensive review of data envelopment analysis (DEA) approach in energy efficiency," Renewable and Sustainable Energy Reviews, vol. 70, pp. 1298-1322, 2017.

[32] Z. Geng, R. Zeng, Y. Han, Y. Zhong, and H. Fu, "Energy efficiency evaluation and energy saving based on DEA integrated affinity propagation clustering: case study of complex petrochemical industries," Energy, vol. 179, pp. 863-875, 2019.

[33] R. C. Marques, S. Berg, and S. Yane, "Nonparametric benchmarking of Japanese water utilities: institutional and environmental factors affecting efficiency," Journal of Water Resources Planning and Management, vol. 140, no. 5, pp. 562-571, 2014.

[34] K. Li and B. Lin, "Impact of energy conservation policies on the green productivity in China's manufacturing sector: Evidence from a three-stage DEA model," Applied Energy, vol. 168, pp. 351-363, 2016.

[35] C. Stewart, R. Matousek, and T. N. Nguyen, "Efficiency in the Vietnamese banking system: a DEA double bootstrap approach," Research in International Business and Finance, vol. 36, pp. 96-111, 2016.

[36] J. Wu, B. Xiong, Q. An, J. Sun, and H. Wu, "Total-factor energy efficiency evaluation of Chinese industry by using twostage DEA model with shared inputs," Annals of Operations Research, vol. 255, no. 1-2, pp. 257-276, 2017.

[37] A. Hatami-Marbini, P. J. Agrell, M. Tavana, and P. Khoshnevis, "A flexible cross-efficiency fuzzy data envelopment analysis model for sustainable sourcing," Journal of Cleaner Production, vol. 142, pp. 2761-2779, 2017.

[38] H. Li, H. He, J. Shan, and J. Cai, "Innovation efficiency of semiconductor industry in China: a new framework based on generalized three-stage DEA analysis," Socio-Economic Planning Sciences, vol. 66, pp. 136-148, 2018.

[39] A. Tajbakhsh and E. Hassini, "Evaluating sustainability performance in fossil-fuel power plants using a two-stage data envelopment analysis," Energy Economics, vol. 74, pp. 154178, 2018.

[40] T. Sueyoshi and Y. Yuan, "Measuring energy usage and sustainability development in Asian nations by DEA 
intermediate approach," Journal of Economic Structures, vol. 7, no. 1, 2018.

[41] M. Huang, Z. Wang, and T. Chen, "Analysis on the theory and practice of industrial symbiosis based on bibliometrics and social network analysis," Journal of Cleaner Production, vol. 213, pp. 956-967, 2019.

[42] Y. Wang, V. K. Thangasamy, Z. Hou, R. L. K. Tiong, and L. Zhang, "Collaborative relationship discovery in BIM project delivery: a social network analysis approach," Automation in Construction, vol. 114, Article ID 103147, 2020.

[43] A. Backiel, B. Baesens, and G. Claeskens, "Predicting time-tochurn of prepaid mobile telephone customers using social network analysis," Journal of the Operational Research Society, vol. 67, no. 9, pp. 1135-1145, 2017.

[44] D. Knoke and J. H. Kuklinski, Network Analysis: Beverly Hills, Sage Publications, Thousand Oaks, CA, USA, 1982.

[45] Z. Li, L. Sun, Y. Geng et al., "Examining industrial structure changes and corresponding carbon emission reduction effect by combining input-output analysis and social network analysis: a comparison study of China and Japan," Journal of Cleaner Production, vol. 162, pp. 61-70, 2017.

[46] J. S. Liu and W.-M. Lu, "DEA and ranking with the networkbased approach: a case of R\&D performance," Omega, vol. 38, no. 6, pp. 453-464, 2010.

[47] J. S. Liu, W.-M. Lu, C. Yang, and M. Chuang, "A networkbased approach for increasing discrimination in data envelopment analysis," Journal of the Operational Research Society, vol. 60, no. 11, pp. 1502-1510, 2009.

[48] D. H. Lee, I. W. Seo, H. C. Choe, and H. D. Kim, "Collaboration network patterns and research performance: the case of Korean public research institutions," Scientometrics, vol. 91, no. 3, pp. 925-942, 2012.

[49] G. Halkos and K. N. Petrou, "Assessing waste generation efficiency in EU regions towards sustainable environmental policies," Sustainable Development, vol. 26, no. 3, pp. 281-301, 2018.

[50] D. Borozan, "Technical and total factor energy efficiency of European regions: a two-stage approach," Energy, vol. 152, pp. 521-532, 2018.

[51] S.-W. Hung, D.-S. He, and W.-M. Lu, "Evaluating the dynamic performances of business groups from the carry-over perspective: a case study of Taiwan's semiconductor industry," Omega, vol. 46, pp. 1-10, 2014.

[52] L.-C. Hsu, "Using a decision-making process to evaluate efficiency and operating performance for listed semiconductor companies," Technological and Economic Development of Economy, vol. 21, no. 2, pp. 301-331, 2015.

[53] W. D. Cook, L. Liang, and J. Zhu, "Measuring performance of two-stage network structures by DEA: a review and future perspective," Omega, vol. 38, no. 6, pp. 423-430, 2010.

[54] Y. Chen, W. D. Cook, N. Li, and J. Zhu, "Additive efficiency decomposition in two-stage DEA," European Journal of Operational Research, vol. 196, no. 3, pp. 1170-1176, 2009.

[55] D. K. Despotis, G. Koronakos, and D. Sotiros, "Composition versus decomposition in two-stage network DEA: a reverse approach," Journal of Productivity Analysis, vol. 45, no. 1, pp. 71-87, 2016.

[56] L. Liang, W. D. Cook, and J. Zhu, "DEA models for two-stage processes: game approach and efficiency decomposition," Naval Research Logistics, vol. 55, no. 7, pp. 643-653, 2008.

[57] W. D. Cook and J. Zhu, Data Envelopment Analysis: A Handbook of Modeling Internal Structure and Network, Springer, Berlin, Germany, 2014.
[58] C. Guo, R. Abbasi Shureshjani, A. A. Foroughi, and J. Zhu, "Decomposition weights and overall efficiency in two-stage additive network DEA," European Journal of Operational Research, vol. 257, no. 3, pp. 896-906, 2017.

[59] K. Tone, M. Tsutsui, and D. E. A. Network, "Network DEA: a slacks-based measure approach," European Journal of Operational Research, vol. 197, no. 1, pp. 243-252, 2009.

[60] S. Wasserman and K. Faust, Social Network Analysis: Methods and Applications, Cambridge University Press, Cambridge, UK, 1994.

[61] S. P. Borgatti and R. Cross, "A relational view of information seeking and learning in social networks," Management Science, vol. 49, no. 4, pp. 432-445, 2003.

[62] L. C. Freeman, D. Roeder, and R. R. Mulholland, "Centrality in social networks: II experimental results," Social Networks, vol. 2, no. 2, pp. 119-141, 1979.

[63] P. Bonacich, "Power and centrality: a family of measures," American Journal of Sociology, vol. 92, no. 5, pp. 1170-1182, 1987.

[64] A. A. Batabyal and H. Beladi, "Artists, engineers, and aspects of economic growth in a creative region," Economic Modelling, vol. 71, pp. 214-219, 2018. 